\title{
Correction: Spenger et al. Glutaric Aciduria Type I Missed by Newborn Screening: Report of Four Cases from Three Families. Int. J. Neonatal Screen. 2021, 7, 32
}

\author{
Johannes Spenger $^{1}{ }^{\mathbb{D}}$, Esther M. Maier ${ }^{2}$, Katharina Wechselberger ${ }^{3} \mathbb{D}$, Florian Bauder ${ }^{3} \mathbb{D}$, Melanie Kocher $^{4}$, \\ Wolfgang Sperl ${ }^{1}$, Martin Preisel ${ }^{1}$, Katharina A. Schiergens ${ }^{2}$, Vassiliki Konstantopoulou ${ }^{5}$, Wulf Röschinger ${ }^{6}$, \\ Johannes Häberle $^{7}$, Thomas Schmitt-Mechelke ${ }^{3} \mathbb{D}$, Saskia B. Wortmann ${ }^{1}$ and Ralph Fingerhut ${ }^{7,8, *,+}(\mathbb{D}$
}

check for updates

Citation: Spenger, J.; Maier, E.M.; Wechselberger, K.; Bauder, F.; Kocher, M.; Sperl, W.; Preisel, M.; Schiergens, K.A.; Konstantopoulou, V.; Röschinger, W.; et al. Correction: Spenger et al. Glutaric Aciduria Type I Missed by Newborn Screening: Report of Four Cases from Three Families. Int. J. Neonatal Screen. 2021, 7, 32. Int. J. Neonatal Screen. 2022, 8, 2 https://doi.org/10.3390/ ijns8010002

Received: 14 December 2021 Accepted: 15 December 2021 Published: 31 December 2021

Publisher's Note: MDPI stays neutral with regard to jurisdictional claims in published maps and institutional affiliations.

Copyright: (C) 2021 by the authors. Licensee MDPI, Basel, Switzerland. This article is an open access article distributed under the terms and conditions of the Creative Commons Attribution (CC BY) license (https:// creativecommons.org/licenses/by/ $4.0 /)$.
1 Department of Pediatrics, Salzburger Landeskliniken (SALK) and Paracelsus Medical University (PMU), 5020 Salzburg, Austria; j.spenger@salk.at (J.S.); w.sperl@salk.at (W.S.); m.preisel@salk.at (M.P.); s.wortmann-hagemann@salk.at (S.B.W.)

2 Division of Metabolism, Dr. von Hauner Children's Hospital, D-80337 Munich, Germany; esther.maier@med.uni-muenchen.de (E.M.M.); katharina.schiergens@med.uni-muenchen.de (K.A.S.)

3 Division of Neuropediatrics, Children's Hospital Lucerne, CH-6004 Lucerne, Switzerland; katharina.wechselberger@luks.ch (K.W.); florian.bauder@luks.ch (F.B.); thomas.schmitt@luks.ch (T.S.-M.)

4 Kinderarztpraxis Arche, CH-3270 Aarberg, Switzerland; melanie.kocher@gmx.com

5 Austrian Newborn Screening Program, Department of Pediatrics and Adolescent Medicine, Medical University of Vienna, 1090 Vienna, Austria; vassiliki.konstantopoulou@meduniwien.ac.at

6 Division of Newborn Screening, Laboratory Becker \& Colleagues, D-81671 Munich, Germany; w.roeschinger@labor-becker.de

7 Division of Metabolism and Children's Research Center, University Children's Hospital Zurich, CH-8032 Zurich, Switzerland; Johannes.Haeberle@kispi.uzh.ch

8 Swiss Newborn Screening Laboratory, University Children's Hospital Zurich, CH-8032 Zurich, Switzerland

* Correspondence: Ralph.Fingerhut@synlab.com; Tel.: +49-961-309-327; Fax: +49-961-309-224

† Present Address: Division of Newborn Screening, Synlab MVZ Weiden GmbH, D-92363 Weiden, Germany.

There was an error in the original publication [1]. In patient 2 and 3 , a mutation (p.Arg257Glu) is mistakenly documented. Instead, the mutation is p.Arg257Gln. A correction has been made to Section 2. Case Reports, 2.2. Case 2, Paragraph 3; Section 2. Case Reports, 2.3. Case 3, Paragraph 1; Section 3. Results, Paragraph 1; Section 4. Discussion, Paragraph 1:

Section 2. Case Reports, 2.2. Case 2, Paragraph 3: At the age of 10 years, genetic testing revealed previously described compound heterozygous variants in GCDH (p.Arg257Gln, p.Met405Val) [11,12], confirming the diagnosis of GA-1.

Section 2. Case Reports, 2.3. Case 3, Paragraph 1: After the diagnosis was made (compound heterozygous variants in GCDH: p.Arg257Gln and p.Met405Val), she was admitted during an infection with poor oral intake, and a clear deterioration of the movement disorder was observed.

Section 3. Results, Paragraph 1: Patients 2 and 3 were compound heterozygous for p.Arg257Gln and p.Met405Val, patient 1 was compound heterozygous for p.Gly241Val and p.Gly390Ala, and patient 4 was compound heterozygous for p.Arg257Trp and the novel variant p.Lys170Asn.

Section 4. Discussion, Paragraph 1: Patients 2 and 3 are compound heterozygous for a previously described severe mutation (p.Arg257Gln) with $0 \%$ residual activity [11] and a milder mutation (p.Met405Val) with $4-25 \%$ residual activity that is more prevalent in African patients [12] 
The authors apologize for any inconvenience caused and state that the scientific conclusions are unaffected. The original publication has also been updated.

\section{Reference}

1. Spenger, J.; Maier, E.M.; Wechselberger, K.; Bauder, F.; Kocher, M.; Sperl, W.; Preisel, M.; Schiergens, K.A.; Konstantopoulou, V.; Röschinger, W.; et al. Glutaric Aciduria Type I Missed by Newborn Screening: Report of Four Cases from Three Families. Int. J. Neonatal Screen. 2021, 7, 32. [CrossRef] [PubMed] 